\title{
Reguladores vegetais no desenvolvimento e produtividade da cana-de-açúcar
}

\author{
Glauber Henrique Pereira Leite ${ }^{(1)}$ e Carlos Alexandre Costa Crusciol(1)
}

(1)Universidade Estadual Paulista, Faculdade de Ciências Agronômicas, Departamento de Produção Vegetal, Caixa Postal 237, CEP 18610-307 Botucatu, SP. E-mail: ghpleite@fca.unesp.br, crusciol@fca.unesp.br

\begin{abstract}
Resumo - O objetivo deste trabalho foi avaliar o desenvolvimento e a produtividade de colmos de cana-de-açúcar, resultantes da aplicação de reguladores vegetais no iníco da safra. Ostratamentos consistiram na aplicação de três reguladores vegetais inibidores de crescimento - sulfometuron metil, glifosato e compostos de radicais carboxílicos orgânicos + glifosato - e na maturação natural como testemunha, em delineamento experimental em blocos ao acaso, com cinco repetições. Os maturadores retardam o processo de crescimento em altura das plantas, sem afetar o número e o diâmetro de colmos na colheita, e influenciam de forma e intensidade distintas a ocorrência do florescimento e chochamento. O glifosato proporciona elevados índices de brotação lateral e prejudica a rebrota da soqueira. Os maturadores induzem o aumento do teor de açúcares redutores totais, o que contribui para a melhoria da qualidade tecnológica da cana-de-açúcar.
\end{abstract}

Termos para indexação: Saccharum officinarum, biometria, glifosato, inibidores do crescimento, maturação, sulfometuron metil.

\section{Growth regulators in the development and productivity of sugarcane}

\begin{abstract}
The objective of this work was to evaluate the development and productivity of sugarcane, due to plant regulators application at the cropping season beginning. The treatments consisted of three plant growth inhibitors - sulfometuron methyl, glyphosate, and compounds of organic carboxilic radicals + glyphosate - and natural ripening as control, in a randomized block design with five replicates. The ripeners hold up the growth process of plant height, without affecting the number and diameter of stems at harvest, however they influence, in different intensities and ways, the flowering and pith process. Glyphosate provide the largest index of bud sprouting and damage of regrowth of the ratoon cane. The ripeners induce increase in sugar reducer total contents, contributing for the improvement in technological quality of sugarcane.
\end{abstract}

Index terms: Saccharum officinarum, biometrics, glyphosate, growth inhibitors, ripening, sulfometuron methyl.

\section{Introdução}

O aumento atual das áreas de cultivo de cana-deaçúcar torna necessário o provimento de matéria-prima de qualidade tecnológica à indústria sucroalcooleira, a fim de propiciar extração econômica. No entanto, as condições climáticas determinantes para a ocorrência do processo de maturação natural - queda gradativa da temperatura e redução da precipitação-, principalmente no início da safra, podem favorecer o desenvolvimento vegetativo em detrimento do acúmulo de sacarose (Deuber, 1988).

A redução no crescimento da cana-de-açúcar pode promover o processo de maturação, efeito este importante para regiões onde a cultura apresenta demasiado desenvolvimento vegetativo, em razão da não ocorrência de condições climáticas adequadas ao processo de maturação natural (Almeida et al., 2003). Castro (2000) relatou que, mesmo sob condições que favorecem a vegetação da cana-de-açúcar, também se pode induzir a maturação pela aplicação de maturadores.

Maturadores, definidos como reguladores vegetais, são compostos químicos capazes de modificar a morfologia e a fisiologia da planta, que podem ocasionar modificações qualitativas e quantitativas na produção. Esses compostos possibilitam, entre outros benefícios, retardar ou inibir o desenvolvimento vegetativo, 
aumentar o teor de sacarose, tornar a maturação precoce e aumentar a produtividade de colmos e açúcar (Lavanholi et al., 2002; Almeida et al., 2003).

O processo de florescimento implica em alterações morfológicas e fisiológicas no vegetal e, na cana-deaçúcar, tem sido considerado prejudicial ao acúmulo de sacarose, uma vez que a formação da flor drena considerável quantidade de sacarose, o que acarreta prejuízos à qualidade da matéria-prima fornecida à indústria sucroalcooleira. O chochamento (ou isoporização) tem início com a ocorrência do processo de florescimento e se caracteriza pelo secamento do interior do colmo e perda de peso final, oriunda da redução do volume de caldo. A depender da variedade e da condição ambiental à que ela está submetida, a intensidade dos processos é variável, bem como a intensidade dos problemas advindos desses fenômenos (Salata \& Ferreira, 1977; Deuber, 1988). Entretanto, a ocorrência da brotação lateral pode implicar a queda da qualidade tecnológica dos colmos, uma vez que a formação desses brotos tardios mobiliza considerável quantidade de energia da planta, em contrapartida ao processo de acúmulo de sacarose.

O objetivo deste trabalho foi avaliar o desenvolvimento e a produtividade de colmos da cana-de-açúcar, em conseqüência da aplicação de reguladores vegetais no início da safra.

\section{Material e Métodos}

$\mathrm{O}$ experimento foi conduzido em cana-soca (segundo corte realizado em 30/4/2003), por dois anos consecutivos (2004 e 2005), na Fazenda São Joaquim, no Município de Igaraçu do Tietê, SP $\left(22^{\circ} 38^{\prime} 45^{\prime \prime} \mathrm{S}, 48^{\circ} 36^{\prime} 29^{\prime \prime} \mathrm{W}\right.$ e altitude de $620 \mathrm{~m}$ ). O clima predominante da região é o Aw (Köppen), seco definido, com temperatura média anual de $21,6^{\circ} \mathrm{C}$, umidade relativa média de $70 \%$, com extremos de $77 \%$ em fevereiro e $59 \%$ em agosto, e precipitação pluvial média de $1.344 \mathrm{~mm}$. Os dados climáticos mensais, referentes às temperaturas máxima, média e mínima, precipitação pluvial e velocidade do vento, durante o período de condução do experimento, foram coletados na Estação Metereológica da Fazenda São Joaquim (Figura 1).

O delineamento experimental foi o de blocos ao acaso, com cinco repetições. Os tratamentos constituíram-se da aplicação de três reguladores vegetais, da classe dos inibidores de crescimento - $15 \mathrm{~g} \mathrm{ha}^{-1}$ de sulfometuron metil; $192 \mathrm{~g} \mathrm{ha}^{-1}$ de glifosato; e $1 \mathrm{~L} \mathrm{ha}^{-1}$ de MTD (compostos de radicais carboxílicos orgânicos CC) $+72 \mathrm{~g} \mathrm{ha}^{-1}$ de glifosato - e a maturação natural como testemunha. Cada parcela foi constituída por oito linhas de $10 \mathrm{~m}$ de comprimento, espaçadas em $1,5 \mathrm{~m}$, contudo, nas avaliações foram consideradas as seis linhas centrais, tendo-se desprezado $1 \mathrm{~m}$ nas extremidades, com total de $72 \mathrm{~m}^{2}$ de área útil.

Utilizou-se a variedade RB855453, reconhecida por apresentar média produtividade de colmos, elevado teor de sacarose, com precocidade de maturação, e média exigência em fertilidade de solo.

A aplicação dos maturadores foi realizada em 29/3/2004 e 29/3/2005, por meio de equipamento costal pressurizado $\left(\mathrm{CO}_{2}\right)$, com barra de $6 \mathrm{~m}$ de comprimento, em forma de $\mathrm{T}$, com seis bicos de pulverização
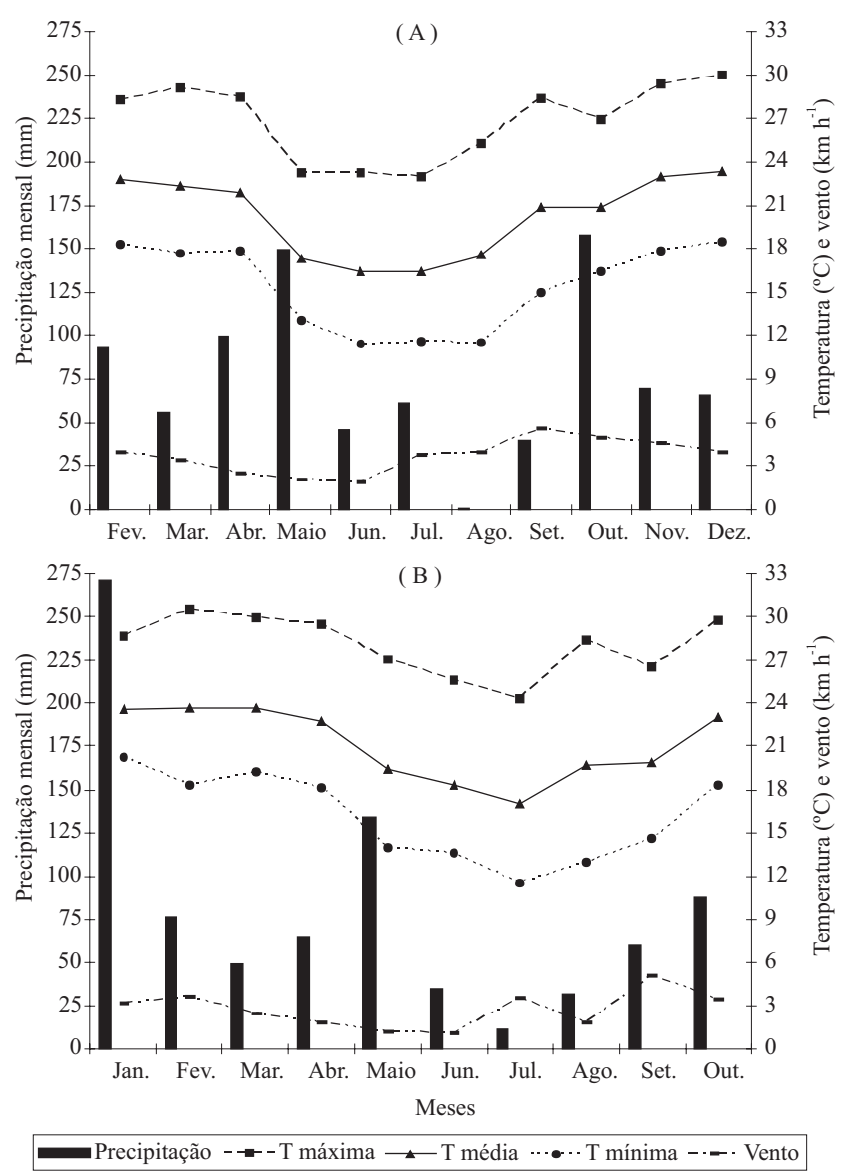

Figura 1. Precipitação mensal, temperaturas máxima, média e mínima e velocidade do vento, registradas durante o período de condução do experimento, na Estação Metereológica da Fazenda São Joaquim, nas safras 2004 (A) e 2005 (B). 
AXI 11002, e a pressão de trabalho foi de 50 PSI, para a vazão de $100 \mathrm{~L} \mathrm{ha}^{-1}$.

A produtividade de colmos (TCH), por ocasião da colheita, foi determinada nas quatro fileiras centrais, e duas fileiras de plantas foram destinadas às mensurações tecnológicas, realizadas a $0,15,30,45,60,75$ e 90 dias após a aplicação (DAA) em 2004, e a 0, 30, 60 e 90 DAA em 2005. Nas duas fileiras de plantas, foi estabelecido $1 \mathrm{~m}$ aleatório, em cada época de amostragem, e os colmos coletados foram submetidos ao desponte na altura da gema apical e à desfolha, e encaminhados para o Laboratório de Bebidas do Departamento de Gestão e Tecnologia Agroindustrial, da Faculdade de Ciências Agronômicas (FCA/Unesp), Campus de Botucatu, para serem processados segundo a metodologia do Sistema de Pagamento de Cana pelo Teor de Sacarose (SPCTS), conforme atualizações semestrais do Consecana, quanto às avaliações tecnológicas descritas em Fernandes (2003), em que o parâmetro considerado são os açúcares redutores totais da cana (ART).

Nas mesmas plantas destinadas à avaliação tecnológica, foram determinadas as variáveis: altura de plantas, diâmetro de colmos, florescimento, chochamento e brotação lateral.

As variáveis altura de plantas e diâmetro dos colmos foram determinadas no momento de instalação do experimento e na colheita, aos 0 e 90 DAA, respectivamente. A altura foi determinada mediante régua graduada em metros, da superfície do solo até a região auricular da folha +1 , de acordo com a numeração sugerida por Kuijper (Dillewijn, 1952), enquanto o diâmetro foi determinado no terceiro entrenó acima da superfície do solo, com o auxílio de paquímetro digital.

O florescimento foi avaliado mediante a observação da alteração morfológica da gema apical, e a brotação lateral foi determinada pela observação da emissão de brotos laterais - mínimo de $10 \mathrm{~cm}$ de comprimento - no terço superior da planta; em relação a ambos os parâmetros, foi determinada, em cada unidade experimental, a relação número de colmos florescidos e número de colmos com brotos laterais, respectivamente, pelo número total de colmos, multiplicado por 100 . Para a determinação do chochamento, foi efetuado o corte longitudinal dos colmos, para verificação da existência de tecido branco e esponjoso característico, cujos resultados foram obtidos da mesma forma descrita anteriormente. As avaliações de florescimento e brotação lateral foram realizadas mensalmente, desde a instalação dos experimentos até o momento da colheita, e o chochamento foi determinado no final do experimento.

$\mathrm{Na}$ colheita, determinou-se, ainda, o número de colmos, enquanto a rebrota da soqueira foi determinada aos 45 dias após a colheita (DAC). Ambos os parâmetros foram avaliados em $10 \mathrm{~m}$ de linha, dentro da área útil de cada parcela e, posteriormente, foram estabelecidos os respectivos valores por metro.

Osresultados foram submetidosà análise devariância, e as médias dos tratamentos foram comparadas pelo teste LSD, a $5 \%$ de probabilidade. Os resultados de épocas de amostragem foram submetidos à análise de regressão, tendo-se adotado, como critério para a escolha do modelo, a magnitude dos coeficientes de regressão significativos a $5 \%$ de probabilidade pelo teste $\mathrm{t}$.

\section{Resultados e Discussão}

$\mathrm{Na}$ safra 2004, a disponibilidade hídrica, de março a julho, o declínio da temperatura, de maio a agosto, favoreceram o desenvolvimento vegetativo da cana-de-açúcar (Figura 1 A). Na safra 2005, o processo de maturação natural foi favorecido pela menor precipitação pluvial no intervalo de maio a julho, com pequenas diferenças em relação à safra anterior, quanto à disponibilidade térmica referente à média mensal (Figura $1 \mathrm{~B}$ ).

Os maturadores retardaram $\mathrm{o}$ processo de crescimento em altura das plantas de cana-de-açúcar, em 2004, que diferiu da maturação natural (Tabela 1). $\mathrm{Na}$ safra subseqüente, aos 90 DAA, determinou-se a menor altura nas plantas tratadas com glifosato, em relação à maturação natural, sem diferenças entre épocas. Provavelmente, esse comportamento ocorreu pelo menor alongamento dos entrenós imaturos, uma vez que esses maturadores podem ocasionar a morte da gema apical, em razão de seu acúmulo nas regiões de crescimento ativo (meristemas). Isto corrobora o relatado por Romero et al. (1998b), que verificaram redução severa na altura das plantas de cana-de-açúcar, decorrente da aplicação de glifosato.

O glifosato inibe a atividade da enzima EPSPS (5-enolpiruvilchiquimato-3-fosfato sintase) e evita a conversão de chiquimato à corismato e a biossíntese 
dos aminoácidos fenilalanina, tirosina e triptofano, precursores de compostos secundários, entre eles os hormônios vegetais (Rizzard et al., 2004). Assim, a biossíntese do ácido indolil acético (AIA) é inibida, uma vez que é sintetizado a partir do triptofano, o qual tem importante função quanto à promoção do alongamento e da divisão celular que se refletem no crescimento em altura das plantas (Rodrigues \& Leite, 2004).

O sulfometuron metil atua pela inibição não competitiva da enzima ALS (acetolactato sintase) ou AHAS (acetohidroxi sintase), na rota de síntese dos aminoácidos ramificados - valina, leucina e isoleucina -, e interfere na síntese protéica, no balanço hormonal e na síntese de DNA, o que implica a paralisação do crescimento (Rizzard et al., 2004).

A aplicação dos maturadores não induziu diferenças no diâmetro dos colmos (Tabela 1), o que permite inferir que a manutenção da integridade da gema apical, embora favorável à continuidade do processo de crescimento em altura das plantas, não tem reflexo significativo no diâmetro dos colmos.

Os tratamentos tenderam a elevar os índices de florescimento em 2005 (Figura 2 B), com o transcorrer das épocas de amostragem; foi determinado o ajuste linear quanto ao glifosato e ao $\mathrm{CC}+$ glifosato e o ajuste quadrático em relação ao sulfometuron metil e à maturação natural, com máxima diferenciação floral aos 88 DAA e índice de 77\%. Conforme Subiros (1990), o momento propício à aplicação de glifosato é

Tabela 1. Altura de plantas (m) e diâmetro dos colmos (mm) de cana-de-açúcar, variedade RB855453, sob efeito de maturadores aos 0 e 90 dias após a aplicação (DAA), em 2004 e $2005^{(1)}$.

\begin{tabular}{|c|c|c|c|c|}
\hline \multirow[t]{2}{*}{ Tratamento } & \multicolumn{2}{|c|}{2004} & \multicolumn{2}{|c|}{2005} \\
\hline & $0 \mathrm{DAA}$ & 90 DAA & $0 \mathrm{DAA}$ & 90 DAA \\
\hline & \multicolumn{4}{|c|}{ Altura de plantas } \\
\hline Maturação natural & $1,97 \mathrm{aB}$ & $2,27 \mathrm{aA}$ & $1,86 \mathrm{aA}$ & $2,22 \mathrm{aA}$ \\
\hline Glifosato & $1,90 \mathrm{aA}$ & $1,97 \mathrm{cA}$ & $1,86 \mathrm{aA}$ & $2,02 \mathrm{bA}$ \\
\hline Sulfometuron metil & $1,97 \mathrm{aA}$ & $2,02 \mathrm{bcA}$ & $1,94 \mathrm{aA}$ & $2,12 \mathrm{abA}$ \\
\hline $\mathrm{CC}^{(2)}+$ glifosato & $1,96 \mathrm{aA}$ & $2,20 \mathrm{abA}$ & $1,86 \mathrm{aA}$ & $2,08 \mathrm{abA}$ \\
\hline \multirow[t]{2}{*}{$\mathrm{CV}(\%)$} & \multicolumn{2}{|c|}{11,22} & \multicolumn{2}{|c|}{6,28} \\
\hline & \multicolumn{4}{|c|}{ Diâmetro de colmos } \\
\hline Maturação natural & $28,78 \mathrm{aA}$ & $31,55 \mathrm{aA}$ & $29,77 \mathrm{aA}$ & $30,97 \mathrm{aA}$ \\
\hline Glifosato & $27,72 \mathrm{aA}$ & $28,90 \mathrm{aA}$ & $30,00 \mathrm{aA}$ & $30,65 \mathrm{aA}$ \\
\hline Sulfometuron metil & $27,57 \mathrm{aA}$ & $30,36 \mathrm{aA}$ & $29,94 \mathrm{aA}$ & $30,57 \mathrm{aA}$ \\
\hline $\mathrm{CC}+$ glifosato & $29,31 \mathrm{aA}$ & $29,36 \mathrm{aA}$ & $29,02 \mathrm{aA}$ & $30,16 \mathrm{aA}$ \\
\hline
\end{tabular}

Pesq. agropec. bras., Brasília, v.43, n.8, p.995-1001, ago. 2008 o início da diferenciação floral, no caso de variedades de cana-de-açúcar que florescem, porém, nas que não florescem, sua aplicação deverá ser realizada quando alcançarem o pleno desenvolvimento vegetativo.

Os elevados índices de florescimento (Figura $2 \mathrm{~A}$ e B) podem ser explicados pelas condições climáticas (Figura 1); as que propiciam a indução floral na região Sudeste do Brasil ocorrem entre 25 de fevereiro e 20 de março, com temperaturas entre 31 e $18^{\circ} \mathrm{C}$ entre o dia e a noite, respectivamente, aliado ao suprimento de água; porém, o processo é controlado também por outros fatores, entre os quais, o fotoperíodo e a radiação solar (Deuber, 1988; Andrade, 2006).

A maturação natural (testemunha) e $\mathrm{CC}+$ glifosato proporcionaram os menores índices de chochamento, em 2004, e diferiram do sulfometuron metil, que, por sua vez, não diferiu do glifosato (Tabela 2), enquanto em 2005 o processo não foi influenciado pelos tratamentos, provavelmente em razão das condições climáticas (Figura 1) associadas ao reduzido número de repetições. Outros resultados de pesquisas têm revelado menores índices de chochamento, pela aplicação de glifosato e sulfometuron metil, em comparação ao controle (Pontin, 1995; Castro et al., 2002).

A brotação lateral aumentou de forma linear com o transcorrer das épocas de amostragem, em relação às aplicações de glifosato e sulfometuron metil em 2004 (Figura 2C), enquanto na safra subseqüente houve efeito quadrático (Figura 2 D). O menor índice de brotação lateral, obtido na testemunha, pode ser explicado pela manutenção da integridade da gema apical, uma vez que o uso dos reguladores vegetais, da classe dos inibidores do crescimento, altera a dominância apical e o balanço hormonal (Rizzard et al., 2004; Rodrigues \& Leite, 2004).

A dominância apical é dada pela contínua síntese endógena de auxina no ápice da planta, que promove a biossíntese de enzimas específicas - que atuam na degradação de polissacarídeos específicos da parede celular, no colmo - e produz oligossacarídeos capazes de inibir o desenvolvimento das gemas que se manteriam dormentes. A remoção da gema apical tem como resposta a quebra de dormência das gemas laterais, uma vez que as oligossacarinas deixam de ser produzidas e liberam a brotação (Castro, 2000).

Pela Figura 2 E e F, foi constatado o aumento do teor de ART, com o transcorrer das épocas de 
amostragem, provavelmente decorrente da maior influência que a sacarose apresenta sobre os açúcares totais, uma vez que, durante o processo de maturação, há redução da intensidade de crescimento, responsável pela demanda de glicose e frutose.
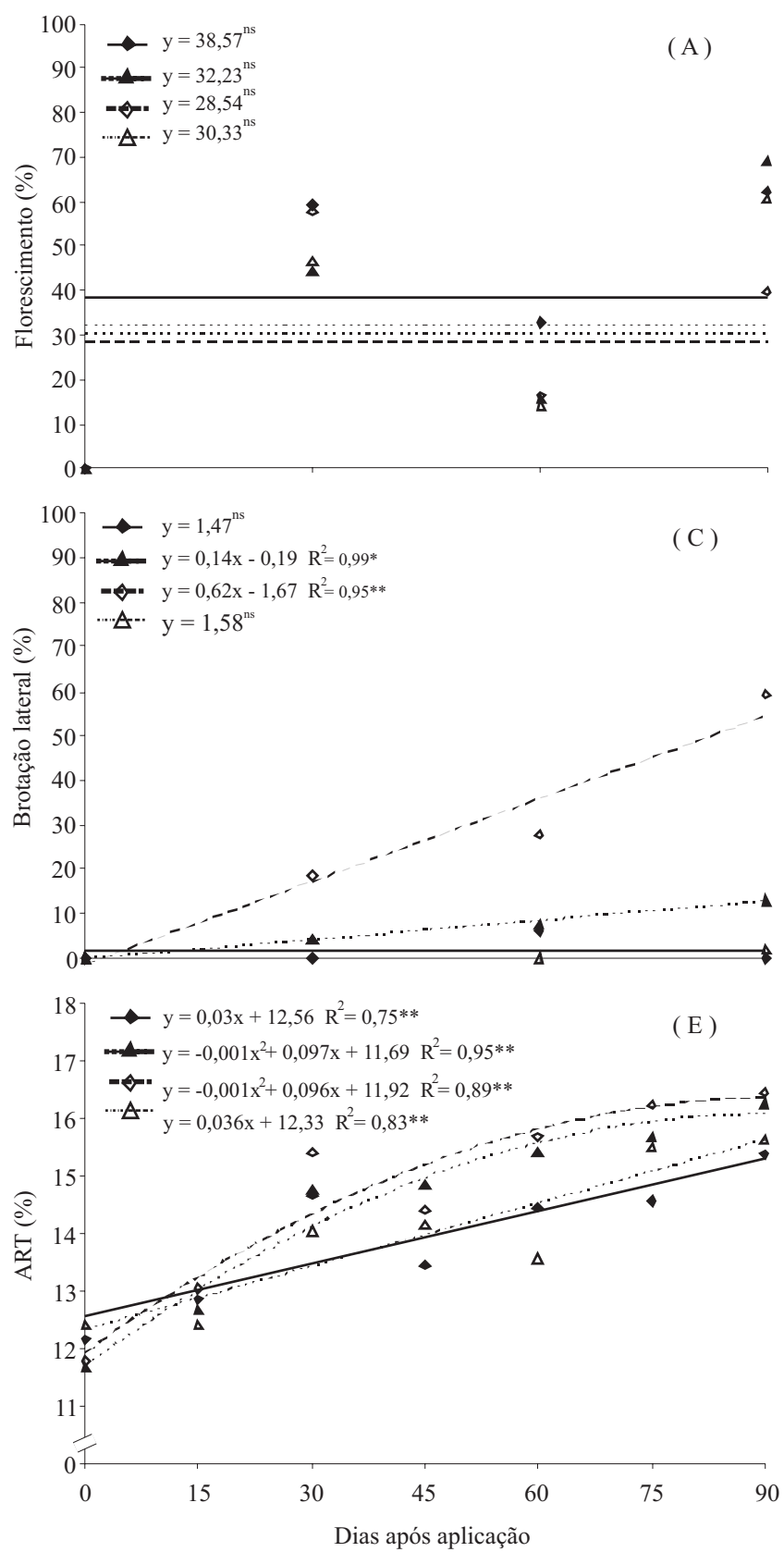

$\mathrm{Na}$ safra 2004, a aplicação de glifosato e de sulfometuron metil apresentou resposta expressa por modelo quadrático positivo, enquanto os tratamentos $\mathrm{CC}+$ glifosato e maturação natural ajustaram-se a modelo linear crescente (Figura 2 E). Em 2005, os
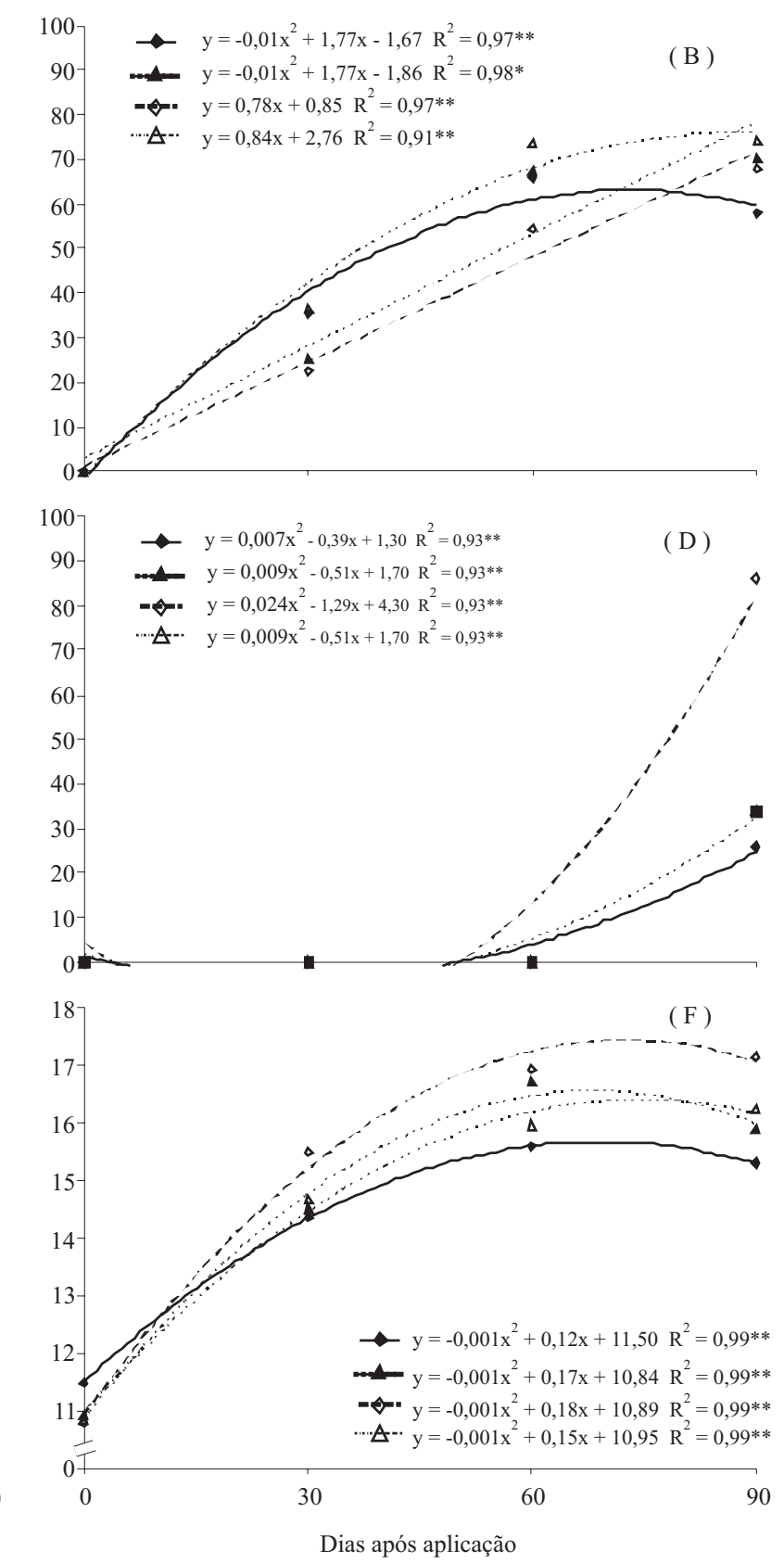

Figura 2. Florescimento, brotação lateral e açúcares redutores totais (ART), em função da aplicação dos tratamentos

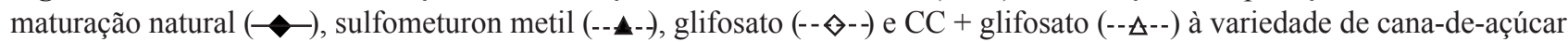

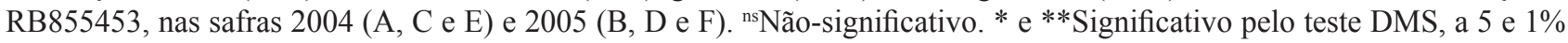
de probabilidade, respectivamente. 
tratamentos induziram aumento e posterior diminuição do teor de ART, demonstrado por função quadrática (Figura $2 \mathrm{~F}$ ), tendo se obtido os maiores teores para as aplicações de glifosato (ART $=19 \%$ ), sulfometuron metil $($ ART $=18 \%), C C+$ glifosato $($ ART $=16,6 \%)$ e maturação natural $($ ART $=15,1 \%)$, aos $85,80,75$ e 60 DAA, respectivamente (Figura $2 \mathrm{~F}$ ).

O ART representa todos os açúcares da cana, na forma de açúcares invertidos, embora outras substâncias redutoras, presentes no caldo de cana, possam estar incluídas. Na planta, o desdobramento da sacarose em glicose e frutose é uma reação de duplo sentido, isto é, ocorre a inversão, assim como a combinação, durante o metabolismo da fotossíntese e respiração da planta; daí a importância do conhecimento do teor de ART, para a avaliação da qualidade da matéria-prima (Fernandes, 2003).

A aplicação dos maturadores proporcionou teores de ART superiores ao encontrado na testemunha, o que

Tabela 2. Intensidade de chochamento e número de colmos aos 90 dias após a aplicação (DAA), rebrota da soqueira aos 45 dias após a colheita (DAC) e produtividade de colmos, na colheita da cana-de-açúcar variedade RB855453, sob efeito de maturadores, em 2004 e $2005^{(1)}$.

\begin{tabular}{|c|c|c|}
\hline Tratamento & 2004 & 2005 \\
\hline & \multicolumn{2}{|c|}{ Chochamento (\%) } \\
\hline Maturação natural & $27,47 b$ & $24,00 \mathrm{a}$ \\
\hline Glifosato & $43,94 \mathrm{ab}$ & $0,00 \mathrm{a}$ \\
\hline Sulfometuron metil & $65,28 \mathrm{a}$ & $28,00 \mathrm{a}$ \\
\hline $\mathrm{CC}^{(2)}+$ glifosato & $28,03 b$ & $16,00 \mathrm{a}$ \\
\hline \multirow[t]{2}{*}{$\mathrm{CV}(\%)$} & 55,92 & 105,36 \\
\hline & \multicolumn{2}{|c|}{ Número de colmos por metro } \\
\hline Maturação natural & $13,00 \mathrm{a}$ & $13,00 \mathrm{a}$ \\
\hline Glifosato & $13,00 \mathrm{a}$ & $13,00 \mathrm{a}$ \\
\hline Sulfometuron metil & $12,00 \mathrm{a}$ & $12,00 \mathrm{a}$ \\
\hline $\mathrm{CC}+$ glifosato & $12,00 \mathrm{a}$ & $13,00 \mathrm{a}$ \\
\hline \multirow[t]{2}{*}{ CV (\%) } & 9,53 & 9,62 \\
\hline & \multicolumn{2}{|c|}{ Produtividade de colmos $\left(\mathrm{Mg} \mathrm{ha}^{-1}\right)$} \\
\hline Maturação natural & $131,00 \mathrm{ab}$ & $113,00 \mathrm{a}$ \\
\hline Glifosato & $126,00 \mathrm{ab}$ & $104,00 \mathrm{bc}$ \\
\hline Sulfometuron metil & $134,00 \mathrm{a}$ & $112,00 \mathrm{ab}$ \\
\hline $\mathrm{CC}+$ glifosato & $123,00 \mathrm{~b}$ & $100,00 \mathrm{c}$ \\
\hline \multirow[t]{2}{*}{$\mathrm{CV}(\%)$} & 7,63 & 11,24 \\
\hline & \multicolumn{2}{|c|}{ Número de brotos por metro } \\
\hline Maturação natural & $21,00 \mathrm{a}$ & $18,00 \mathrm{a}$ \\
\hline Glifosato & $21,00 \mathrm{a}$ & $15,00 \mathrm{~b}$ \\
\hline Sulfometuron metil & $22,00 \mathrm{a}$ & $16,00 \mathrm{ab}$ \\
\hline $\mathrm{CC}+$ glifosato & $20,00 \mathrm{a}$ & $16,00 \mathrm{ab}$ \\
\hline $\mathrm{CV}(\%)$ & 7,51 & 6,98 \\
\hline
\end{tabular}

${ }^{(1)}$ Médias seguidas de letras iguais, na coluna, não diferem entre si pelo teste DMS, a $5 \%$ de probabilidade. ${ }^{(2)}$ Compostos de radicais carboxílicos orgânicos. evidencia a importância desses compostos químicos, no manejo das variedades de cana-de-açúcar, para o objetivo de se explorar o potencial de acúmulo de sacarose.

$\mathrm{O}$ número de colmos por metro, determinado na colheita do experimento, não sofreu influência dos tratamentos, contudo afetou a produtividade de colmos (Tabela 2). Na safra 2004, o tratamento CC + glifosato reduziu de forma significativa este parâmetro, em relação ao sulfometuron metil, que proporcionou a maior massa de colmos por hectare, no entanto, esses dois tratamentos não diferiram da maturação natural. $\mathrm{Na}$ safra subseqüente, os tratamentos glifosato e CC + glifosato apresentaram redução na TCH (Tabela 2), provavelmente em conseqüência da diminuição, no processo de crescimento em altura, das plantas tratadas com glifosato (Tabela 1).

Pesquisas têm revelado redução na produção da cana-de-açúcar, pela aplicação de glifosato (Romero et al., 1998a, 2000), enquanto outros autores afirmaram que o emprego deste agente químico e, também, do sulfometuron metil não provocou efeito nos componentes de rendimento e na produção da cana-deaçúcar (Romero et al., 1998b; Fernandes et al., 2002).

Com relação à rebrota da soqueira da cana-deaçúcar, na safra 2005, foi determinado o menor número de brotos por metro no tratamento com glifosato, que diferiu da maturação natural, e que, por sua vez, revelou o maior valor para esta variável (Tabela 2), fato este que corrobora outros resultados de pesquisas (Romero et al., 1998b, 2000), porém discorda de Romero et al. (1998a), os quais não constataram efeito prejudicial deste agente químico na brotação posterior da canade-açúcar.

\section{Conclusões}

1. Os maturadores retardam o processo de crescimento em altura das plantas, sem afetar o número e o diâmetro de colmos na colheita.

2. Os maturadores influenciam, de formas e intensidades distintas, a ocorrência do processo de florescimento e chochamento.

3. O glifosato proporciona elevados índices de brotação lateral e prejudica a rebrota da soqueira.

4. Os maturadores induzem o aumento no teor de açúcares redutores totais, o que contribui para a melhoria da qualidade tecnológica da cana-de-açúcar. 


\section{Agradecimentos}

À Fundação de Amparo à Pesquisa do Estado de São Paulo e ao Conselho Nacional de Desenvolvimento Tecnológico e Científico, por concessão de bolsas; ao Grupo Cosan - Unidade Barra (Usina da Barra), pela cessão da área experimental.

\section{Referências}

ALMEIDA, J.C.V.; SANOMYA, R.; LEITE, C.F.; CASSINELLI, N.F. Eficiência agronômica de sulfometuron-methyl como maturador na cultura da cana-de-açúcar. Revista STAB, v.21, p.36-37, 2003.

ANDRADE, L.A. de B. Cultura da cana-de-açúcar. In: CARDOSO, M. das G. (Ed.). Produção de aguardente de cana-de-açúcar. 2.ed. rev. e amp. Lavras: Ufla, 2006. p.25-67.

CASTRO, P.R.C. Utilização de reguladores vegetais no sistema de produção da cana-de-açúcar. In: SIMPÓSIO INTERNACIONAL DE FISIOLOGIA DA CANA-DE-AÇÚCAR, 2000, Piracicaba. Anais. Piracicaba: STAB, 2000. 10p. (CD-ROM).

CASTRO, P.R.C.; ZAMBON, S.; SANSÍGOLO, M.A.; BELTRAME, J.A.; NOGUEIRA, M.C.S. Ação comparada de ethrel, fuzilade e roundup, em duas épocas de aplicação, na maturação e produtividade da cana-de-açúcar, variedade SP 70-1143. Revista de Agricultura Piracicaba, v.77, p.23-38, 2002.

DEUBER, R. Maturação da cana-de-açúcar na Região Sudeste do Brasil. In: SEMINÁRIO DE TECNOLOGIA AGRONÔMICA, 4., 1988, Piracicaba. Anais. Piracicaba: Copersucar, 1988. p.33-40.

DILLEWIJN, C. van. Botany of sugarcane. Waltham: Chronica Botanica, 1952. 371p.

FERNANDES, A.C. Cálculos na agroindústria da cana-deaçúcar. Piracicaba: STAB, 2003. 240p.

FERNANDES, A.C.; STUPIELLO, J.P.; UCHOA, P.E. de A. Utilização do curavial para melhoria da qualidade da cana-de-açúcar. Revista STAB, v.20, p.43-46, 2002.
LAVANHOLI, M. das G.D.P.; CASAGRANDE, A.A.; OLIVEIRA, L.A.F.; FERNANDES, G.A.; ROSA R.F. Aplicação de ethephon e imazapyr em cana-de-açúcar em diferentes épocas e sua influência no florescimento, acidez do caldo e teores de açúcares nos colmosvariedade SP 70-1143. Revista STAB, v.20, p.42-45, 2002.

PONTIN, J.C. Avaliação de maturadores vegetais na cana-deaçúcar. Álcool e Açúcar, v.77, p.16-18, 1995.

RIZZARD, M.A.; VARGAS, L.; ROMAN, E.S.; KISSMANN, $\mathrm{K}$. Aspectos gerais do manejo e controle de plantas daninhas. In: VARGAS, L.; ROMAN, E.S. (Ed.). Manual de manejo e controle de plantas daninhas. Bento Gonçalves: Embrapa Uva e Vinho, 2004. p.105-144.

RODRIGUES, T.J.D.; LEITE, I.C. Fisiologia vegetal: hormônios das plantas. Jaboticabal: Funep, 2004. 78p.

ROMERO, E.R.; SCANDALIARIS, J.; RUFINO, M. Respuesta de la caña de azúcar al madurativo glifosato. II. Otros efectos del madurador y recomendaciones de manejo. Avance Agroindustrial, v.19, p.4-7, 1998a.

ROMERO, E.R.; SCANDALIARIS, J.; RUFINO, M.; DURÁN, A.; DIAZ, F. Respuesta de la caña de azúcar a la aplicación de glifosato como madurador. I. Efectos en la calidad fabril e influencia de los factores ambientales. Avance Agroindustrial, v.19, p.7-10, 1998 b.

ROMERO, E.R.; SCANDALIARIS, J.; RUFINO, M.; DURÁN, A.; SOTOMAYOR, L.; QUIROGA, V.; MORALES, M. Actualización de las recomendaciones de manejo de glifosato como madurador de la caña de azúcar. Avance Agroindustrial, v.21, p.22-27, 2000.

SALATA, J.C.; FERREIRA, L.J. Estudo da interferência do florescimento nas qualidades agroindustriais de algumas variedades de cana-de-açúcar. Brasil Açucareiro, v.88, p.19-24, 1977.

SUBIROS, J.F. Efecto de la aplicación de glifosato como madurador en tres cultivares de caña de azúcar. Turrialba, v.40, p.527-534, 1990.

Recebido em 10 de dezembro de 2007 e aprovado em 25 de julho de 2008 